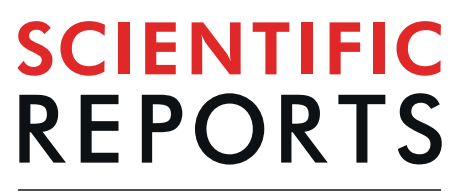

natureresearch

\title{
OPEN Omega-3 fatty acids decrease oxidative stress and inflammation in macrophages from patients with small abdominal aortic aneurysm
}

Received: 25 February 2019

Accepted: 23 August 2019

Published online: 10 September 2019
Lara T. Meital ${ }^{1,2}$, Mark T. Windsor $^{2}$, Maria Perissiou ${ }^{2}$, Karl Schulze $^{3}$, Rebecca Magee $^{4}$, Anna Kuballa ${ }^{1}$, Jonathan Golledge ${ }^{5,6}$, Tom G. Bailey ${ }^{2,7}$, Christopher D. Askew ${ }^{2}$ \& Fraser D. Russell ${ }^{1,2}$

Abdominal aortic aneurysm (AAA) is associated with inflammation and oxidative stress, the latter of which contributes to activation of macrophages, a prominent cell type in AAA. Omega-3 polyunsaturated fatty acids ( $n-3$ PUFAs) have been reported to limit oxidative stress in animal models of AAA. The aim of this study was to evaluate the effect of the $n-3$ PUFA docosahexaenoic acid (DHA) on antioxidant defence in macrophages from patients with AAA. Cells were obtained from men with small AAA (diameter $3.0-4.5 \mathrm{~cm}, 75 \pm 6 \mathrm{yr}, \mathrm{n}=19)$ and age- matched male controls $(72 \pm 5 \mathrm{yr}, \mathrm{n}=41)$ and incubated with DHA for $1 \mathrm{~h}$ before exposure to $0.1 \mu \mathrm{g} / \mathrm{mL}$ lipopolysaccharide (LPS) for $24 \mathrm{~h}$. DHA supplementation decreased the concentration of tumour necrosis factor- $\alpha$ (TNF- $\alpha$; control, $42.1 \pm 13.6$ to $5.1 \pm 2.1 \mathrm{pg} / \mathrm{ml}, \mathrm{p}<0.01 ; \mathrm{AAA}, 25.2 \pm 9.8$ to $1.9 \pm 0.9 \mathrm{pg} / \mathrm{ml}, \mathrm{p}<0.01)$ and interleukin-6 (IL-6; control, $44.9 \pm 7.7$ to $5.9 \pm 2.0 \mathrm{pg} / \mathrm{ml}, \mathrm{p}<0.001 ; \mathrm{AAA}, 24.3 \pm 5.2$ to $0.5 \pm 0.3 \mathrm{pg} / \mathrm{ml}, \mathrm{p}<0.001$ ) in macrophage supernatants. DHA increased glutathione peroxidase activity (control, $3.2 \pm 0.3$ to $4.1 \pm 0.2 \mathrm{nmol} / \mathrm{min} / \mathrm{ml} / \mu \mathrm{g}$ protein, $\mathrm{p}=0.004 ; \mathrm{AAA}, 2.3 \pm 0.5$ to $3.4 \pm 0.5 \mathrm{nmol} / \mathrm{min} / \mathrm{ml} / \mu \mathrm{g}$ protein, $\mathrm{p}=0.008$ ) and heme oxygenase- 1 mRNA expression (control, 1.5 -fold increase, $p<0.001$ ). The improvements in macrophage oxidative stress status serve as a stimulus for further investigation of DHA in patients with AAA.

The long-chain omega-3 polyunsaturated fatty acids (n-3 PUFAs), docosahexaenoic acid (22:6n-3; DHA) and eicosapentaenoic acid (20:5n-3, EPA), have been suggested to have cardioprotective ${ }^{1,2}$, anti-inflammatory ${ }^{3}$, immunoregulatory ${ }^{4}$, antioxidant ${ }^{5,6}$ and anti-tumour activities ${ }^{7}$. These beneficial effects on human health have been attributed to (a) competition with arachidonic acid (AA) for the enzymes involved in the biosynthesis of pro-inflammatory mediator molecules ${ }^{8}$, (b) suppression of pro-inflammatory nuclear factor kappa B (NF- $\kappa$ B) via modulation of toll-like receptor 4 (TLR4) signalling ${ }^{9}$ and activation of peroxisome proliferator-activated receptor gamma $(\operatorname{PPAR} \gamma)^{10}$, (c) activation of the G-protein-coupled receptor free fatty acid receptor 4 (FFA4, formerly GPR120 ${ }^{11}$ and d) metabolism to pro-resolution lipid mediators (e.g. resolvins, protectins, maresins) ${ }^{12,13}$. In synergism with their anti-inflammatory and pro-resolution activities, n-3 PUFAs have recently been documented to suppress pro-oxidant activity by upregulating genes encoding cytoprotective antioxidant proteins such as heme oxygenase 1 (HO-1) and glutathione peroxidase $(\mathrm{GPx})^{14-16}$. HO-1 is a single, transmembrane $32-\mathrm{kDa}$ protein that plays a central role in stress adaptation ${ }^{17}$. HO-1 provides cells and tissues with an inducible antioxidant defence mechanism that can be ubiquitously activated in response to elevated levels of heme, its natural substrate, and a multiplicity of endogenous factors such as heavy metals, cytokines, hormones, growth factors, nitric oxide and

${ }^{1}$ Centre for Genetics, Ecology \& Physiology, School of Health and Sport Sciences, University of the Sunshine Coast, Sippy Downs, Qld, Australia. ${ }^{2}$ VasoActive Group, School of Health and Sport Sciences, University of the Sunshine Coast, Sippy Downs, Qld, Australia. ${ }^{3}$ Sunshine Vascular, Buderim, Old, Australia. ${ }^{4}$ Sunshine Coast University Hospital, Birtinya, Old, Australia. ${ }^{5}$ Queensland Research Centre for Peripheral Vascular Disease, College of Medicine and Dentistry, James Cook University, Townsville, Australia. ${ }^{6}$ Department of Vascular and Endovascular Surgery, Townsville Hospital, Townsville, Australia. ${ }^{7}$ Centre for Research on Exercise, Physical Activity and Health, School of Human Movement and Nutrition Sciences, The University of Queensland, St. Lucia, Qld, Australia. Correspondence and requests for materials should be addressed to F.D.R. (email: frussell@usc.edu.au) 


\section{Control}

A

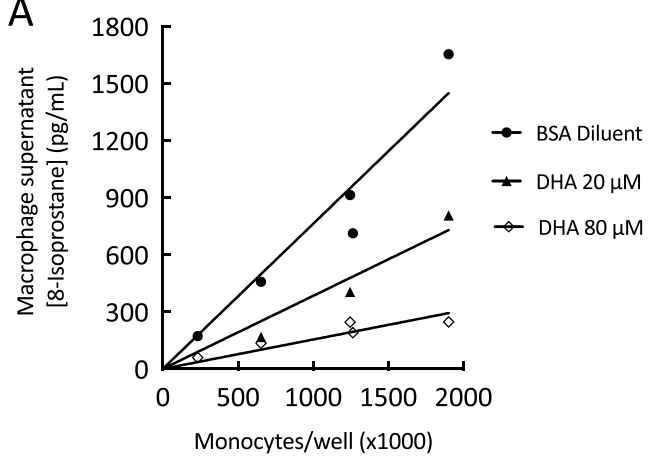

AAA

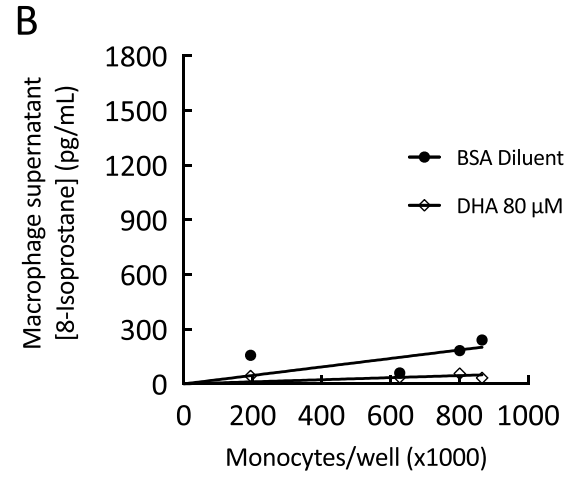

Figure 1. Concentration of 8-isoprostane in supernatants of monocyte-derived macrophages obtained from control participants and AAA patients. Monocytes were isolated from whole blood, grown in culture and, following spontaneous differentiation into macrophages, exposed to a $24 \mathrm{~h}$ incubation with $0.1 \mu \mathrm{g} /$ $\mathrm{ml}$ lipopolysaccharide (LPS) prior to collection of the cells and supernatants. LPS-stimulated 8-isoprostane production ( $\mathrm{pg} / \mathrm{ml}$ ), plotted against total number of circulating monocytes present in whole blood samples, was lower in AAA (B) compared to control macrophage supernatants (A). DHA decreased LPS-stimulated 8 -isoprostane production in a dose-dependent manner in control participant macrophages. A non-significant trend for decreased 8-isoprostane production was observed in macrophages from AAA patients.

endotoxins ${ }^{17}$. The enzyme's robust ability to defend against oxidative insults is linked to the removal of reactive, pro-oxidant heme and to the biological effects of biliverdin, bilirubin, and carbon monoxide, the three reaction products ${ }^{18}$. The GPx family includes eight phylogenetically related antioxidant enzymes (GPxs 1-8) with essential, location-specific physiological effects involving the reduction of $\mathrm{H}_{2} \mathrm{O}_{2}$ to water and the detoxification of organic hydroperoxides to their corresponding alcohols ${ }^{19}$. By readily decomposing peroxides generated under a variety of physiological conditions, GPx enzymes play a vital role in limiting the strength and extent of reactive oxygen signals and contribute importantly to oxidation-reduction homeostasis and cellular protection ${ }^{20}$.

While n-3 PUFAs have been suggested to limit adverse outcomes associated with inflammation, oxidative stress and disturbed antioxidant status, a deeper understanding of the therapeutic potential of these bioactive nutrients is required in patient populations with conditions characterised by inflammation and oxidative overload such as abdominal aortic aneurysm (AAA). This study aimed to evaluate the effect of DHA on antioxidant defence in macrophages from patients with and without AAA. The HO- 1 inhibitor, SnPP $(10 \mu M)$, and FFA4 receptor antagonist, AH7614 $(2 \mu \mathrm{M})$, were used to examine mechanisms underlying n-3 PUFA effects.

\section{Results}

DHA inhibited 8-isoprostane production. Incubation of cells with DHA decreased LPS-stimulated 8 -isoprostane production in a dose-dependent manner in macrophages from healthy control participants (Fig. 1A). The slope for non-DHA treated data (BSA diluent; $\mathrm{R}^{2}=0.93$ ) was 7.3 -fold greater than that of the DHA $80 \mu \mathrm{M}$ data $\left(\mathrm{R}^{2}=0.83, \mathrm{p}=0.002\right)$. Although LPS-stimulated 8 -isoprostane production was suppressed in macrophages from the AAA patient cohort, a trend towards a further decrease in 8-isoprostane levels was observed when these cells were incubated with DHA (Fig. 1B).

DHA uniformly inhibited cytokine production. DHA-supplemented macrophages from control participants produced lower levels of TNF- $\alpha$ (Fig. $2 \mathrm{~A} ; 20 \mu \mathrm{M} \mathrm{p}<0.001,80 \mu \mathrm{M} \mathrm{p}=0.004$ ), IL-6 (Fig. 2C; $20 \mu \mathrm{M} \mathrm{p}=0.002$, $80 \mu \mathrm{M} \mathrm{p}<0.001$ ), IL-1 $\beta$ (Fig. $2 \mathrm{E} ; 20 \mu \mathrm{M} \mathrm{p}=0.005,80 \mu \mathrm{M} \mathrm{p}=0.004$ ) and IL-10 (Fig. 2I; $20 \mu \mathrm{M} \mathrm{p}=0.004,80 \mu \mathrm{M}$ $\mathrm{p}=0.002)$ compared to non-supplemented cells. In AAA patient macrophages, DHA supplementation suppressed the production of TNF- $\alpha$ (Fig. $2 \mathrm{~B} ; 80 \mu \mathrm{M} \mathrm{p}=0.006$ ), IL-6 (Fig. $2 \mathrm{D} ; 20 \mu \mathrm{M} \mathrm{p}<0.001,80 \mu \mathrm{M} \mathrm{p}<0.001$ ) and IL-10 (Fig. 2J; $20 \mu \mathrm{M} \mathrm{p}=0.008,80 \mu \mathrm{M} \mathrm{p}=0.004$ ). A non-significant decrease was observed for IL-1 $\beta$ (Fig. 2E). DHA supplementation did not alter TGF- $\beta$ levels in macrophages from either the control (Fig. 2G) or AAA (Fig. 2H) cohorts. The effects of oleic acid on cytokine levels were similar to those of DHA. While CHD was evident in two thirds of the AAA cohort, no significant difference in cytokine concentrations (IL-6, IL-1 $1 \beta$, TNF- $\alpha$, IL-10, TGF- $\beta$ ) was observed for these patients when compared to non-CHD patients.

DHA increased GPx activity in monocyte-derived macrophages. DHA supplementation had no effect on catalase activity in macrophages obtained from control (Fig. 3A) or AAA participants (Fig. 3B). GPx activity was significantly increased in control and AAA macrophages supplemented with $80 \mu \mathrm{M}$ DHA (control Fig. 3C, $\mathrm{p}=0.005$; AAA, Fig. 3D, $\mathrm{p}=0.008$ ).

DHA increased HO-1 expression in monocyte-derived macrophages. DHA supplementation induced a 50\% increase in HO-1 mRNA in non-stimulated macrophages $(p<0.001)$ and a trend for increase (39\%) was observed in macrophages exposed to hemin and LPS (Fig. 4A). The induction of HO-1 in macrophages stimulated with hemin and LPS was accompanied by decreases in concentrations of 8 -isoprostane in supernatants from these cells ( $p<0.01$; Fig. 4B). 
A

Control

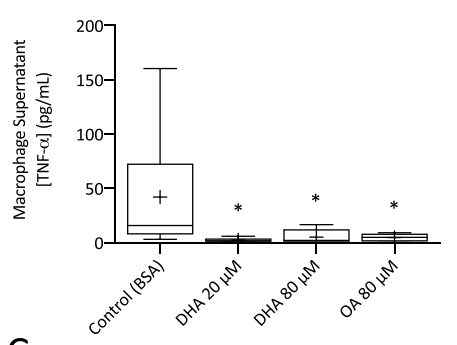

C

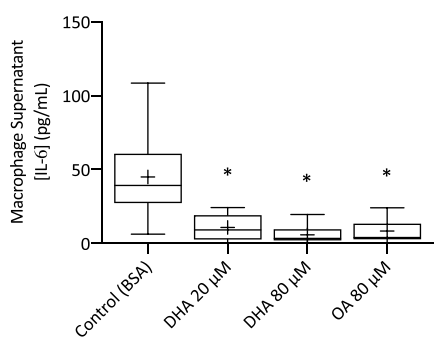

E

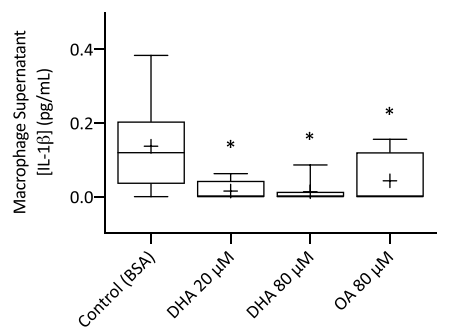

G

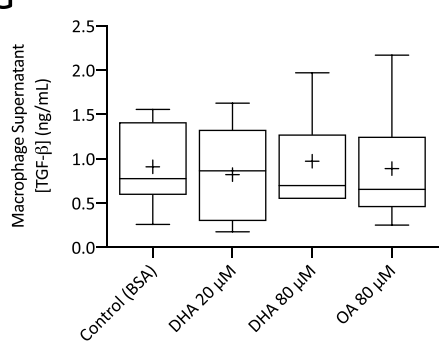

I

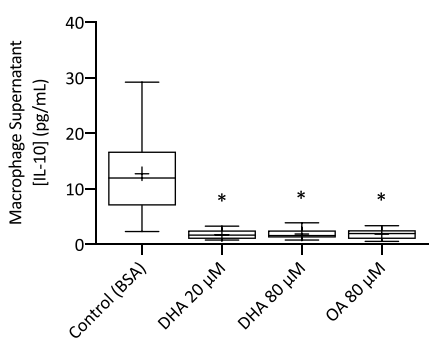

AAA

B

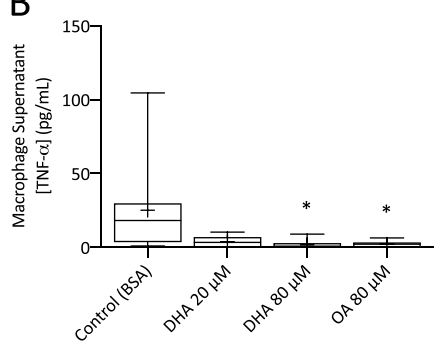

D

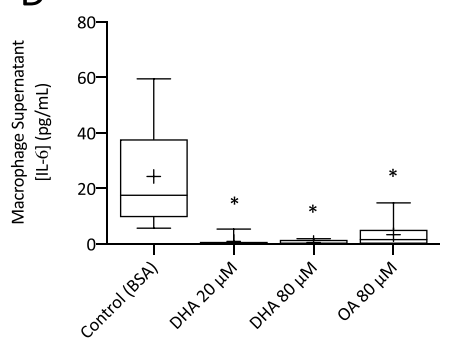

F

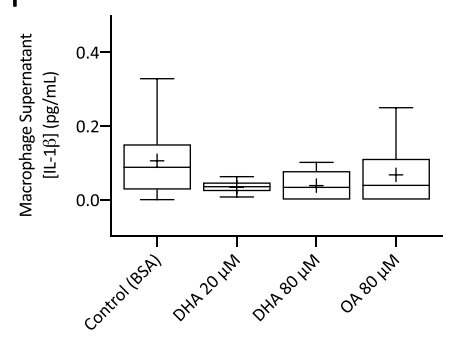

$\mathrm{H}$

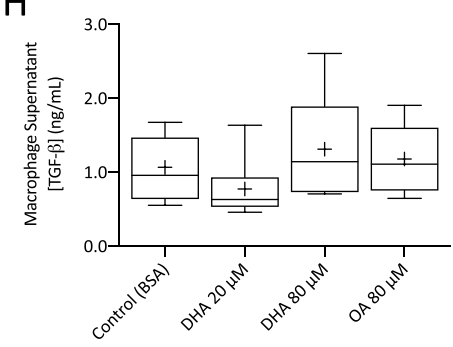

J

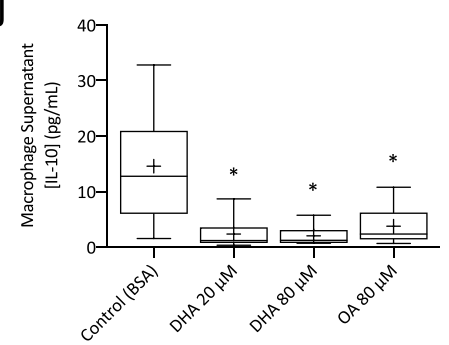

Figure 2. Cytokine concentrations in macrophage supernatants obtained from control participants and AAA patients. Control DHA-supplemented non-stimulated macrophages $(20 \mu \mathrm{Mn}=5-9 ; 80 \mu \mathrm{M}, \mathrm{n}=7-10)$ produced lower levels of tumour necrosis factor alpha (TNF- $\alpha$; A), interleukin-6 (IL-6; C), interleukin-1 $\beta$ (IL- $\beta$; E) and interleukin-10 (IL-10; I) compared to non-supplemented macrophages. DHA supplementation of AAA non-stimulated patient macrophages $(20 \mu \mathrm{M} \mathrm{n}=6-7 ; 80 \mu \mathrm{M}, \mathrm{n}=8-10)$ decreased the production of TNF- $\alpha$ (B), IL-6 (D) and IL-10 (J). A trend toward decreased levels of IL- $\beta(\mathbf{F} ; 20 \mu \mathrm{M} \mathrm{n}=7 ; 80 \mu \mathrm{M} \mathrm{n}=10)$ was observed. Transforming growth factor- $\beta$ (TGF- $\beta$ ) levels in both control (G) and AAA (H) macrophages were unaffected by DHA supplementation. * $\mathrm{p}<0.05$. 
Control

A

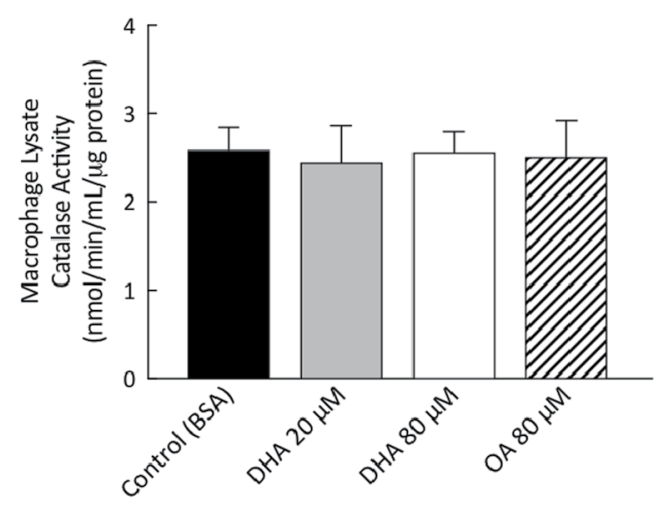

C

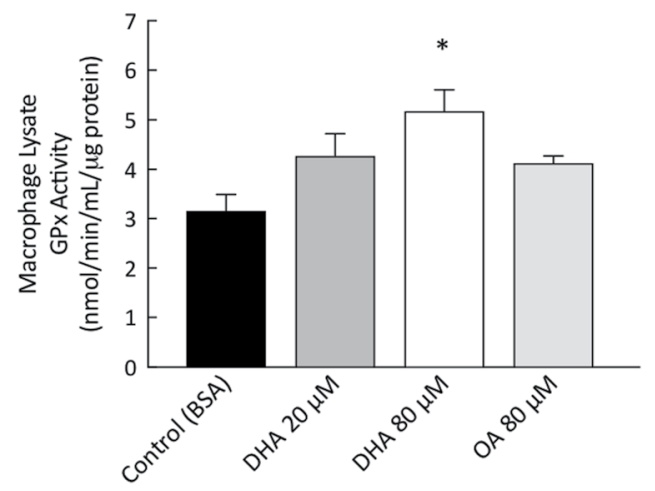

AAA

B

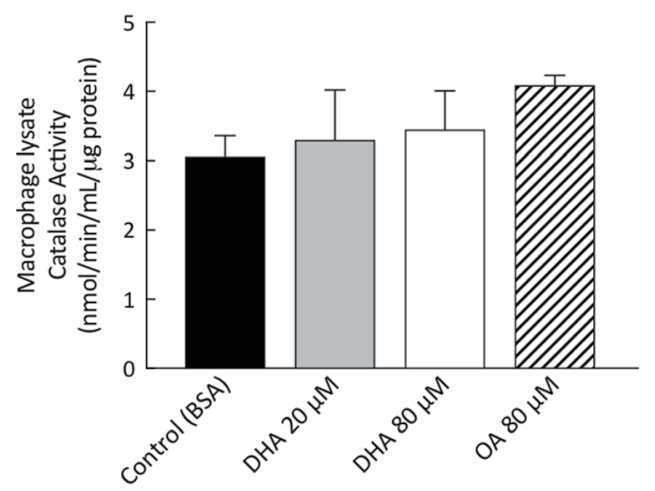

$\mathrm{D}$

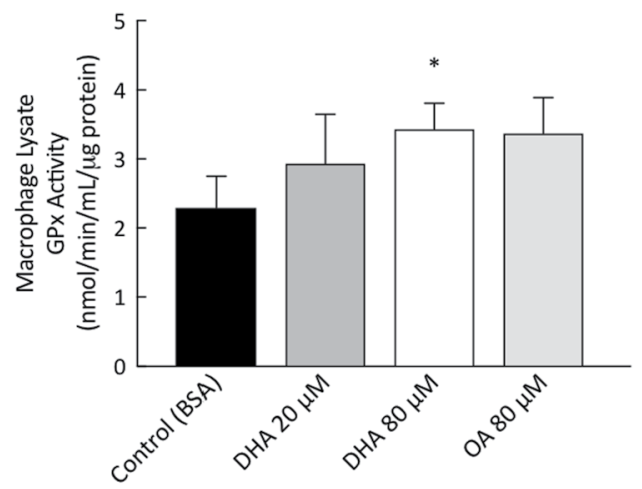

Figure 3. Antioxidant enzyme activity levels in control participant and AAA patient monocyte-derived macrophage lysates. Macrophage catalase activity was unaffected by DHA supplementation in control participants (A) and AAA patients (B). DHA supplementation increased glutathione peroxidase (GPx) activity in non-stimulated macrophages from control participants (C) and patients with AAA (D). Catalase and GPx activity and expression levels were unaffected by supplementation with OA. *p $<0.05$.

DHA, SnPP and AH7614 did not adversely affect cell viability. U937 cell viability was determined in LPS-stimulated cells pre-treated with DHA and/or SnPP or AH7614 using the MTT assay. No adverse change in cell viability was detected for any of the treatment conditions at the concentrations used in this study (Table 1).

The protective effect of DHA was partially reversed by the heme oxygenase inhibitor SnPP. DHA supplementation decreased 8-isoprostane production in LPS-stimulated U937 cells (Fig. 5A), an effect that was not reversed by pre-treatment of the cells with the FFA4 antagonist AH7614 (Fig. 5B). Pre-treatment of cells with the heme oxygenase inhibitor SnPP increased 8-isoprostane production to a level above that of LPS alone (Fig. 5C). A trend for reduced 8-isoprostane levels was observed in LPS-stimulated cells treated with SnPP and DHA.

DHA exhibited modest free radical-scavenging activity. DHA and EPA exhibited modest scavenging activity for the stable DPPH free radical at $30 \mathrm{~min}$ ( $28 \%$ and $24 \%$ respectively) in comparison to positive controls (quercetin and BHT; Fig. 6). OA showed negligible free radical scavenging activity.

\section{Discussion}

Macrophages feature prominently in human and experimental AAA formation and growth. The use of macrophages in this investigation contributed to the pre-clinical evaluation of $n-3$ PUFAs as a novel therapeutic strategy in AAA and uncovered mechanisms underlying n-3 PUFA-mediated improvements in oxidative stress status. Supplementation with the n-3 PUFA, DHA, suppressed production of 8-isoprostane, the gold standard biomarker of oxidative stress and a specific marker of lipid peroxidation ${ }^{21}$, in monocyte-derived macrophages obtained from patients with AAA. The results concord with data from both experimental animal studies ${ }^{22,23}$ and human clinical trials $^{24,25}$ that suggest n-3 PUFAs decrease 8 -isoprostane levels and ease oxidative stress. Importantly, the decrease observed in levels of 8 -isoprostane in supplemented monocyte-derived macrophages suggests highly unsaturated n-3 PUFAs such as DHA do not increase susceptibility to lipid peroxidation. This contention is supported by the 
A

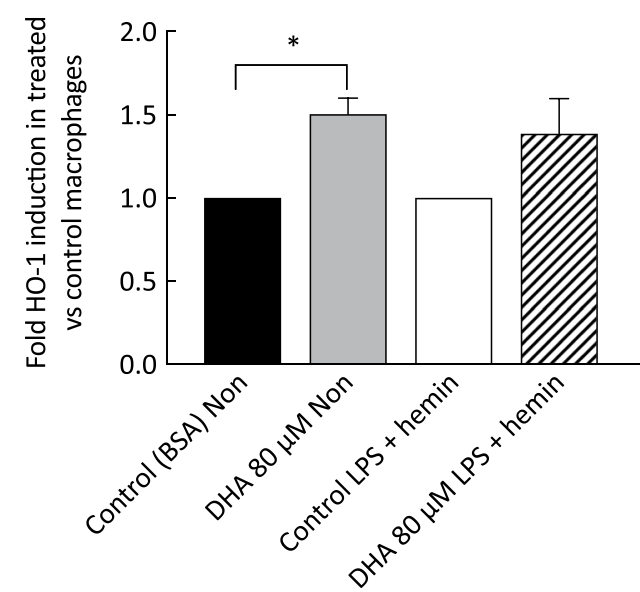

B

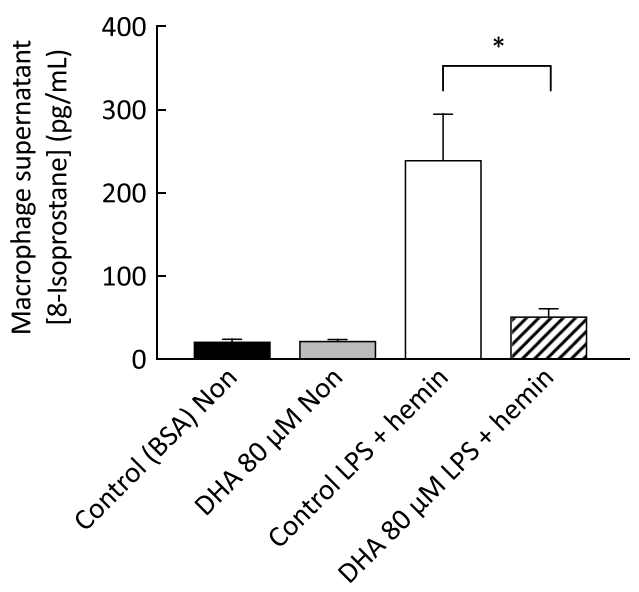

Figure 4. Increase in HO-1 transcripts and decrease in 8-isoprostane concentration in monocyte-derived macrophages from control participants. Real-time quantitative PCR, with raw data normalised to GAPDH, indicated increased HO-1 expression levels in DHA-supplemented non-stimulated macrophages and a trend for increase in LPS-stimulated macrophages exposed to DHA (A). In parallel, significant decreases were observed in 8-isoprostane concentrations in supernatants from hemin- and LPS-stimulated macrophages (B). Values are mean \pm SEM of duplicate determinations $(n=5) . * p<0.05$.

\begin{tabular}{|l|l|}
\hline Compound & LPS-stimulated (\% of control) \\
\hline Albumin (control cells) & 100 \\
\hline DHA $20 \mu \mathrm{M}$ & $109.04 \pm 8.75$ \\
\hline DHA $80 \mu \mathrm{M}$ & $99.71 \pm 3.26$ \\
\hline SnPP $10 \mu \mathrm{M}$ & $110.43 \pm 4.80$ \\
\hline SnPP $10 \mu \mathrm{M}+$ DHA $20 \mu \mathrm{M}$ & $112.34 \pm 6.63$ \\
\hline SnPP $10 \mu \mathrm{M}+$ DHA $80 \mu \mathrm{M}$ & $103.37 \pm 5.91$ \\
\hline AH7614 $2 \mu \mathrm{M}$ & $110.58 \pm 9.05$ \\
\hline AH7614 $2 \mu \mathrm{M}+$ DHA $20 \mu \mathrm{M}$ & $120.52 \pm 7.31$ \\
\hline AH7614 $2 \mu \mathrm{M}+$ DHA $80 \mu \mathrm{M}$ & $105.12 \pm 7.82$ \\
\hline
\end{tabular}

Table 1. Effect of DHA, SnPP and AH7614 on cell viability. Abbreviations: DHA - docosahexaenoic acid, SnPP - tin protoporphyrin.

results of a pre-clinical study that indicated n-3 PUFA-mediated improvements in murine redox status were a consequence of reduced omega- 6 fatty acid peroxidation and diversion away from the peroxyl radical pathway of $\mathrm{F}_{2}$-isoprostane formation ${ }^{26}$. It is noteworthy that the LPS-stimulated 8-isoprostane response in AAA macrophages was suppressed compared to control macrophages. This finding is in line with our previous report of an abrogated cytokine response to LPS in a AAA patient cohort, consistent with endotoxin tolerance ${ }^{27}$.

8 -isoprostanes are stable, robust prostaglandin-like molecules formed independently of cyclooxygenase enzymes as a consequence of reactive oxygen species (ROS)-mediated peroxidation of esterified arachidonic acid ${ }^{28}$. Isoprostanes are released to their free acid form by phospholipase action and the activity of platelet-activating factor acetylhydrolase following their in situ generation from arachidonic acid ${ }^{29}$. Available evidence suggests quantification of these compounds accurately assesses total $\mathrm{F}_{2}$-isoprostane production and provides a highly precise time-integrated index of oxidation status ${ }^{21}$.

In addition to favourable impacts on multiple aspects of the oxidative stress response, n-3 PUFAs are well documented to down-regulate pro-inflammatory processes ${ }^{30,31}$ and to quench injury-, infection- and exercise-induced inflammatory conditions $\mathrm{s}^{32,33}$. The mechanism for the anti-inflammatory effects of $\mathrm{n}-3$ PUFAs has been attributed to activation of FFA4 receptors, resulting in preservation of inhibitor of $\kappa \mathrm{B}$ (I $\kappa \mathrm{B}$ ) and prevention of nuclear translocation of $\mathrm{NF}^{11} \mathrm{~B}^{11}$. Our data showed DHA-supplemented macrophages from both control participants and patients with AAA produced lower levels of the pro-inflammatory cytokines TNF- $\alpha$ and IL- 6 in response to a pro-inflammatory stimulus. The anti-inflammatory and resolution-directed activities described for DHA represent an indirect mechanism by which n-3 PUFAs lower endogenous ROS and positively impact cellular redox status. Activated leukocytes are known to generate powerful oxidants during phagocytosis and to propagate a pro-oxidant milieu by producing cytokines (TNF- $\alpha$, IL-6) that stimulate ROS generation by endothelial cells and other leukocytes ${ }^{34}$. Omega-3 PUFA interference with pro-inflammatory pathways reduces leukocyte activity and decreases leukocyte-mediated ROS production to favourably impact oxidative stress status ${ }^{35}$. 
A

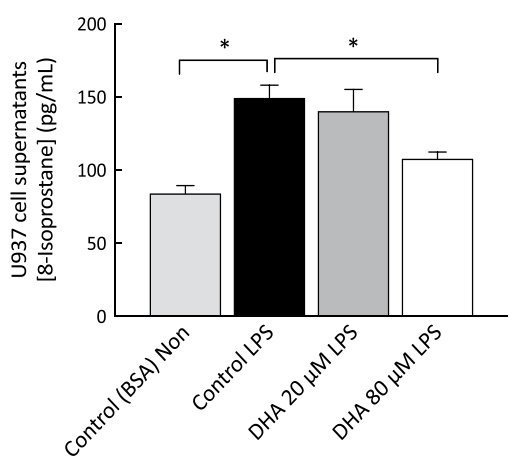

B

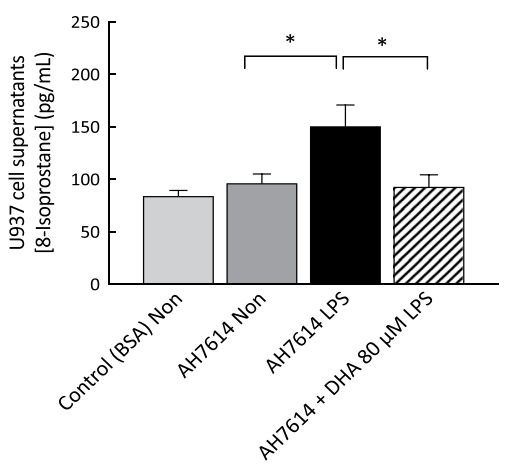

C

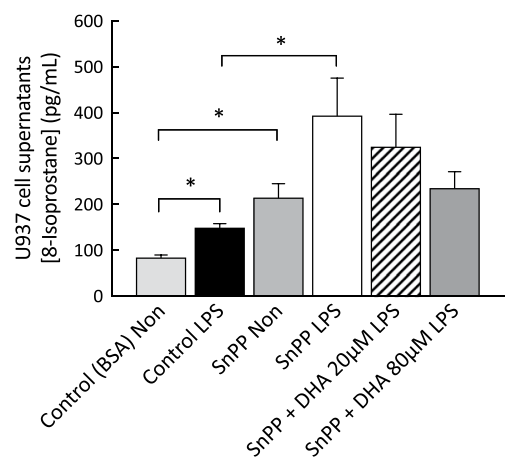

Figure 5. 8-Isoprostane levels in non-stimulated and LPS-stimulated U937 cells incubated in the presence and/or absence of DHA $(20 \mu \mathrm{M} ; 80 \mu \mathrm{M})$, the FFA4 antagonist AH7614 and the HO-1 inhibitor SnPP. Supplementation of cells with DHA $80 \mu \mathrm{M}$ decreased 8-isoprostane production (A), a finding that was not reversed with AH7614 treatment (B). In LPS-stimulated cells treated with SnPP (C), no significant effect was observed for DHA at either of the concentrations tested. Data are expressed as mean $\pm \mathrm{SEM}$ and are representative of at least six independent experiments. ${ }^{*} \mathrm{p}<0.05$.

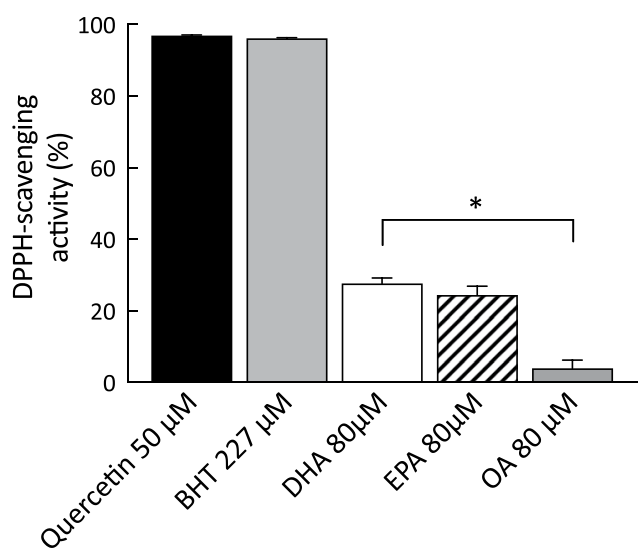

Figure 6. Free radical scavenging activity of quercetin $50 \mu \mathrm{M}$, BHT $227 \mu \mathrm{M}, \mathrm{DHA} 80 \mu \mathrm{M}, \mathrm{EPA} 80 \mu \mathrm{M}$ and OA $80 \mu \mathrm{M}$ as measured by colorimetric 1,1-diphenyl-2-picrylhydrazyl (DPPH) assay. Quercetin and BHT were included as positive controls. Absorbance values for the diluent (BSA) were subtracted from all data sets. Data are expressed as mean \pm SEM and are representative of four independent experiments.

This study examined more direct mechanisms underlying n-3 PUFA-mediated improvements in oxidative stress by evaluating their impact on antioxidant enzymes and determining their capacity to scavenge ROS. Evidence of increased activity levels of GPx was found in non-stimulated macrophages treated with DHA in addition to increased levels of HO-1 mRNA in non-stimulated cells (50\% increase) and a trend for increased levels in LPS-stimulated cells (39\% increase). To investigate mechanisms underlying DHA-mediated suppression of 8-isoprostane production, additional experiments were carried out in a macrophage cell line. In these experiments, exposure of U937 cells to the FFA4 receptor antagonist AH7614 failed to reverse the suppressive effects of DHA on macrophage 8-isoprostane formation. This finding suggests that the FFA4 receptor is not the effector protein in DHA-mediated improvements in oxidative stress status. In further experiments, exposure of U937 cells to the heme oxygenase inhibitor SnPP increased 8-isoprostane production to a level above that of LPS alone and a trend for reduced 8-isoprostane levels was observed in LPS-stimulated cells treated with SnPP and DHA. Failure of the HO-1 inhibitor to fully reverse the protective effects of DHA suggests that n-3 PUFAs decrease oxidative stress through multiple pathways. In support of this, and in synergism with their positive impacts on inflammation and cytoprotective enzymatic antioxidants, n-3 PUFAs were shown to exhibit a modest capacity to scavenge free radicals (DHA, 28\%; EPA, 24\%) in comparison to oleic acid, which had negligible free radical scavenging activity, and the positive controls quercetin and BHT which had high levels of free radical scavenging activity.

While an in vitro cell culture system is subject to inherent limitations, our use of native, non-immortalised and non-transformed primary cells allowed a biologically relevant representation of the unique responses of AAA and control macrophages to supplementation with DHA. It is of note that the results obtained for 8-isoprostane and GPx in supplemented monocyte-derived AAA macrophages mirror the results of a recent n-3 PUFA 


\begin{tabular}{|c|c|c|}
\hline Variable & $\begin{array}{l}\text { AAA Patients } \\
(n=19)\end{array}$ & $\begin{array}{l}\text { Control Participants } \\
(\mathrm{n}=41)\end{array}$ \\
\hline Age (years) & $74.6 \pm 5.8$ & $71.9 \pm 5.1$ \\
\hline \multicolumn{3}{|l|}{ Smoking: } \\
\hline Never & $7(37 \%)$ & $17(41 \%)$ \\
\hline Past & $10(53 \%)$ & $24(59 \%)$ \\
\hline Current & $2(11 \%)$ & $0(0 \%)$ \\
\hline $\mathrm{BMI}\left(\mathrm{kg} \cdot \mathrm{m}^{2}\right)$ & $26.9 \pm 2.9$ & $26.0 \pm 4.1$ \\
\hline Systolic blood pressure (mmHg) & $136.5 \pm 13.6$ & $137.92 \pm 13.2$ \\
\hline Diastolic blood pressure (mmHg) & $78.6 \pm 6.1$ & $79.4 \pm 8.3$ \\
\hline Hypertension & $12(63 \%)$ & $15(37 \%)$ \\
\hline Diabetes & $2(11 \%)$ & $0(0 \%)$ \\
\hline Coronary heart disease $^{\dagger}$ & $12(63 \%)$ & $4(10 \%)$ \\
\hline \multicolumn{3}{|l|}{ Medication } \\
\hline Low-dose aspirin & $5(26 \%)$ & $3(7 \%)$ \\
\hline \multicolumn{3}{|l|}{ Anti-hypertensive agents: } \\
\hline Beta blockers $^{\dagger}$ & $8(42 \%)$ & $5(12 \%)$ \\
\hline Angiotensin II receptor antagonists & $6(32 \%)$ & $7(17 \%)$ \\
\hline ACE inhibitors & $2(11 \%)$ & $3(7 \%)$ \\
\hline Calcium channel blockers & $2(11 \%)$ & $3(7 \%)$ \\
\hline Diuretics & $2(11 \%)$ & $2(5 \%)$ \\
\hline Statins $^{\dagger}$ & $14(74 \%)$ & $13(32 \%)$ \\
\hline
\end{tabular}

Table 2. Demographic, biometric and medical characteristics of AAA patients and control participants $($ mean $\pm \mathrm{SD})$. ${ }^{\dagger}$ Significantly different to control (Fisher's exact test, $\left.\mathrm{p}<0.05\right)$. AAA, abdominal aortic aneurysm; BMI, body mass index; NSAIDs, non-steroidal anti-inflammatory drugs.

supplementation trial conducted by our group in a cohort of AAA patients (unpublished findings). While clinical evidence regarding n-3 PUFA efficacy in AAA patient populations is limited, low serum concentrations of n-3 PUFAs have been associated with larger aneurysm size and a faster growth rate in a Japanese AAA cohort ${ }^{36}$. In addition, animal studies using an angiotensin II-infused $\mathrm{ApoE}^{-1-}$ mouse model have reported decreased oxidative stress signalling and reduced matrix metalloproteinase expression following n-3 PUFA supplementation ${ }^{37,38}$. Further long-term clinical studies will be required to determine whether n-3 PUFA-mediated improvements in oxidative stress translate into positive alterations in the histopathologic appearance of AAA at the level of the aorta.

Taken together, the findings of this study suggest the antioxidant potential of n-3 PUFAs arises from their ability, via multiple means, to lower endogenous ROS levels and positively impact cellular redox status. In addition to direct ROS scavenging, n-3 PUFAs suppress pro-inflammatory cytokine signalling and induce and/or activate cytoprotective antioxidant enzymes. Given the critical role of macrophages in the development and progression of AAA disease, the positive impact of DHA on macrophage pro-inflammatory responses serves as a stimulus for further investigation of this fatty acid in patients with AAA.

\section{Materials and Methods}

Participants. Patients with AAA were recruited from Sunshine Coast public and private clinics (Table 2). Control participants included members of the University of the Third Age and the general population of the Sunshine Coast, Queensland. The study was approved by the University of the Sunshine Coast (A/13/473 and A/16/833) and the Prince Charles Hospital Human Research Ethics Committees (HREC/12/QPCH/13). All experiments were performed in accordance with relevant guidelines and regulations. Written informed consent was obtained for each participant and all consented participants completed the study. The patient group included 19 men with AAA (mean maximal diameter $37.8 \pm 5.3 \mathrm{~mm}$ ) and the control group included 41 men without a documented AAA. AAA is known to be much more common in men than in women ${ }^{39}$ and male gender is associated with a 4 -fold higher risk of $\mathrm{AAA}^{40}$. In addition, we have reported recently that differences exist in erythrocyte fatty acid incorporation for men and women ${ }^{41}$. While cells were obtained from all participants, limited supernatant volumes precluded their inclusion in all experimental assays. Aneurysm size, evaluated as part of routine care and AAA surveillance, was confirmed with transabdominal ultrasound. Exclusion criteria for AAA patients and control participants included: age below 60 or above 86 years, BMI above $39 \mathrm{~kg} \mathrm{~m}^{-2}$, uncontrolled hypertension, cardiac arrhythmia, heart failure, symptomatic aortic stenosis, chronic obstructive pulmonary disease, chronic inflammatory disease and regular use of prescription anti-inflammatory medication. A family history of AAA or known aneurysmal disease served as additional exclusion criteria for control participants. Dietary and medical history questionnaires were used to ensure adherence to inclusion/exclusion criteria. All participants refrained from non-prescribed anti-inflammatory medications $72 \mathrm{~h}$ prior to blood collection and abstained from alcohol and caffeine for the $12 \mathrm{~h}$ leading up to their study visit. 
Fatty acid preparation. Fatty acids used in experiments included docosahexaenoic acid (C22:6n-3; DHA), eicosapentaenoic acid (C20:5n-3; EPA) and oleic acid (C18:1n-9; OA). Stock solutions (15 mM) of the fatty acids were prepared as previously described ${ }^{42}$. Control cells were supplemented with bovine serum albumin (BSA).

U937 cell culture and cell viability assay. Human myelo-monocytic lymphoma U937 cells (American Type Culture Collection, USA) were used in this study to uncover mechanisms underlying n-3 PUFA-mediated alterations in inflammatory and oxidative stress status. Immortalised macrophage-like cell lines offer the advantages of ready availability and extensive proliferative potential and use of these cells allowed cellular responses to treatments to be studied under controlled conditions. U937 cells were maintained in RPMI 1640 medium (Sigma, USA) supplemented with 10\% foetal calf serum (FCS; Gibco, USA), $1000 \mathrm{U} / \mathrm{ml}$ penicillin (Gibco, USA), and $1000 \mu \mathrm{g} / \mathrm{ml}$ streptomycin (Gibco, USA) in $25 \mathrm{~cm}^{2}$ or $75 \mathrm{~cm}^{2}$ tissue culture flasks (Corning, USA) at $37^{\circ} \mathrm{C}$ humidified atmosphere with $5 \% \mathrm{CO}_{2}$ and sub-cultured every $4^{\text {th }}$ or $5^{\text {th }}$ day. Following growth to confluence, cells were seeded onto 24-well culture plates (Corning Costar, USA) at a density of $4 \times 10^{5}$ cells/well and differentiation was induced by exposure of cells to phorbol 12-myristate 13-acetate (PMA; Sigma, USA; 20 nM; 24h). Cells were allowed to mature for a further $46-48 \mathrm{~h}$ in fresh complete medium prior to a $2 \mathrm{~h}$ exposure to the FFA 4 receptor antagonist AH7614 $(2 \mu \mathrm{M}, \mathrm{n}=6)$ or the heme oxygenase inhibitor tin protoporphyrin $(\mathrm{SnPP} ; 10 \mu \mathrm{M}, \mathrm{n}=9)$. These concentrations of agents would be anticipated to inhibit $96.2 \%$ of FFA4 receptors ${ }^{43}$ and $99.9 \%$ of HO- $1^{44}$. Cells were incubated with media containing bovine serum albumin $(80 \mu \mathrm{M}, \mathrm{BSA}$, control cells), EPA $(20 \mu \mathrm{M}, \mathrm{n}=6$; $80 \mu \mathrm{M}, \mathrm{n}=6)$ or DHA $(20 \mu \mathrm{M}, \mathrm{n}=6 ; 80 \mu \mathrm{M}, \mathrm{n}=6)$ for a further $2 \mathrm{~h}$. Treated U937 cells were exposed to lipopolysaccharide from Escherichia coli (LPS; $0.1 \mu \mathrm{g} / \mathrm{ml}$, Serotype 0111:B4; Sigma, USA) for $6 \mathrm{~h}$ followed by collection and centrifugation $\left(10,000 \times \mathrm{g}, 5 \mathrm{~min}, 4^{\circ} \mathrm{C}\right)$ of the supernatants. Supernatants used to measure 8 -isoprostane were preserved with butylhydroxytoluene (BHT; $2.5 \mathrm{mg} / \mathrm{ml}$ ) to prevent artefactual 8-isoprostane formation. Cell viability was measured after treatment with AH7614 and SnPP using a commercially available colorimetric Cell Proliferation (MTT) Kit (Roche Diagnostics, Germany) in accordance with manufacturer's instructions.

Monocyte isolation protocol. Whole blood was collected in ethylenediaminetetraacetic acid (EDTA) tubes $(4 \times 6 \mathrm{ml})$ and centrifuged $\left(400 \times \mathrm{g}, 25 \mathrm{~min}, 18^{\circ} \mathrm{C}\right)$ with the brake turned off. The buffy coat was collected and diluted with $8 \mathrm{ml} \mathrm{Ca}{ }^{2+} / \mathrm{Mg}^{2+}$-free Dulbecco's phosphate buffered solution containing $1 \mathrm{mM}$ EDTA (DPBS, $\mathrm{pH} 7.1)$ and centrifuged $\left(150 \times \mathrm{g}, 18^{\circ} \mathrm{C}, 10 \mathrm{~min}\right.$, brake off $)$. The wash was repeated twice and the final spin was followed by removal of the supernatant and resuspension of cells with $1 \mathrm{ml}$ of DPBS. Resuspended cells were layered to the surface of $2 \mathrm{ml}$ aliquots of Ficoll-Paque Premium 1.073 (GE Healthcare, Sweden), the preparation was centrifuged $\left(400 \times \mathrm{g}, 30 \mathrm{~min}, 18^{\circ} \mathrm{C}\right)$ and cells within a dense white mononuclear band were collected and diluted with $5 \mathrm{ml}$ DPBS. The cells were pelleted by centrifugation $\left(500 \times \mathrm{g}, 10 \mathrm{~min}, 18^{\circ} \mathrm{C}\right)$ and the supernatant was discarded. Monocyte purification was achieved by centrifugation with hyperosmotic Percoll Plus (Sigma, USA; prepared as per ${ }^{45}$ ) or by discontinuous density centrifugation using isotonic Percoll Plus at densities $1.070 \mathrm{~g} /$ $\mathrm{ml}, 1.062 \mathrm{~g} / \mathrm{ml}, 1.060 \mathrm{~g} / \mathrm{ml}$ and $1.058 \mathrm{~g} / \mathrm{ml}$. The Percoll preparation was centrifuged $\left(400 \times \mathrm{g}, 15 \mathrm{~min}, 21^{\circ} \mathrm{C}\right)$ and monocytes within a band located at the interface of the Percoll solution and the DPBS/media were collected and diluted with $4 \mathrm{ml}$ DPBS. The cells were pelleted by centrifugation $\left(550 \times \mathrm{g}, 10 \mathrm{~min}, 21^{\circ} \mathrm{C}\right)$ and the supernatant was discarded. An aliquot of the cell pellet $(1 \mu \mathrm{l})$ was stained with May-Grunwald stain (Merck Millipore) to confirm the presence of monocytes. Monocytes were resuspended in $1 \mathrm{ml}$ serum-free complete Iscove's Modified Dulbecco's Medium (IMDM) supplemented with $1000 \mathrm{U} / \mathrm{ml}$ penicillin (Gibco, USA), $1000 \mu \mathrm{g} / \mathrm{ml}$ streptomycin (Gibco, USA) and $2 \mathrm{mM} \mathrm{L-glutamine} \mathrm{(Gibco,} \mathrm{USA)} \mathrm{and} \mathrm{cell} \mathrm{number} \mathrm{was} \mathrm{determined} \mathrm{using} \mathrm{a} \mathrm{haemocytometer.}$

Autologous serum preparation. Whole blood from each participant was collected in serum separator tubes $(2 \times 6 \mathrm{ml})$ and allowed to clot at $22^{\circ} \mathrm{C}$ for $30 \mathrm{~min}$ prior to centrifugation $\left(1500 \times \mathrm{g}, 15 \mathrm{~min}, 15^{\circ} \mathrm{C}\right)$. The serum was collected, centrifuged $\left(4000 \times \mathrm{g}, 5 \mathrm{~min}, 4^{\circ} \mathrm{C}\right)$ and the supernatant was stored at $-80^{\circ} \mathrm{C}$ for use as an autologous serum supplement in cell cultures of isolated monocytes.

Monocyte culture. Monocytes were seeded onto 24 well culture plates (Corning Costar, USA) at a density of $3 \times 10^{5}$ cells/well (final volume $600 \mu \mathrm{l} /$ well). Plated cells were transferred to a $37^{\circ} \mathrm{C}$ humidified $5 \% \mathrm{CO}_{2}$ incubator for a period of $2 \mathrm{~h}$, at which time the supernatant containing non-adherent cells was removed following gentle flushing and the medium was replaced with IMDM containing $5 \%$ autologous serum (v/v) and $50 \mathrm{ng} / \mathrm{ml}$ macrophage colony-stimulating factor (M-CSF, Sigma, USA). Further media changes occurred on days 1 and 4.

Macrophage maturation and activation. Monocytes matured into a morphologically heterogeneous macrophage population over 7 days. On day 7, the medium (IMDM and all additives except M-CSF) was replaced for a final time and the adherent macrophages were exposed to a $1 \mathrm{~h}$ treatment with BSA (control cells), DHA $(20 \mu \mathrm{M}$ or $80 \mu \mathrm{M})$ or OA $(80 \mu \mathrm{M})$. The fatty acid concentrations used in the supplementation of cells have been documented to have no adverse effects on cell viability ${ }^{46,47}$ and have been shown to approximate the plasma DHA concentration, previously reported to be in the range of $91-122 \mu \mathrm{M}^{48}$. To measure 8-isoprostane, treated cells were polarised toward an M1 phenotype through exposure to $20 \mathrm{ng} / \mathrm{ml}$ interferon gamma (IFN- $\gamma$ ) and $0.1 \mu \mathrm{g} / \mathrm{ml} \mathrm{LPS}$ for a further $24 \mathrm{~h}$. LPS is a well-characterised activator of TLR4, which is known to be expressed in human macrophages. Elevated LPS levels have been associated with some AAA cases ${ }^{49,50}$, although this association remains a contentious issue ${ }^{51,52}$. All supernatants were collected, centrifuged $\left(10,000 \times \mathrm{g}, 5 \mathrm{~min}, 4^{\circ} \mathrm{C}\right)$ and aliquoted with and without BHT $(2.5 \mathrm{mg} / \mathrm{ml})$. For glutathione peroxidase (GPx) activity assays, a $300 \mu \mathrm{l}$ aliquot of GPx collection buffer ( $50 \mathrm{mM}$ Tris-HCl, pH 7.5, $5 \mathrm{mM}$ EDTA, $1 \mathrm{mM} \mathrm{DTT}$ ) was added to each well and adherent cells were harvested and stored at $-80^{\circ} \mathrm{C}$. For catalase activity assays, a $300 \mu \mathrm{l}$ aliquot of catalase collection buffer $(50 \mathrm{mM}$ $\mathrm{KH}_{2} \mathrm{PO}_{4}$, pH 7.0, containing $1 \mathrm{mM}$ EDTA) was added to each well and adherent cells were harvested and stored at $-80^{\circ} \mathrm{C}$. 
Measurement of free 8-isoprostane. To establish oxidative stress status, free 8-isoprostane levels were measured in BHT-preserved U937 and monocyte-derived macrophage supernatants without further manipulation using a commercially available enzyme immunoassay kit (Cayman Chemical Company, Ann Arbor, USA) in accordance with manufacturer's instructions. Samples were stored at $-80^{\circ} \mathrm{C}$ and assayed within 30 days of collection.

Cytokine assays. Cytokines (IL-6, TGF- $\beta$, TNF- $\alpha$, IL-1 $\beta$, IL-10) were measured in monocyte-derived macrophage supernatants using commercially available enzyme immunoassay kits (Affymetrix eBioscience, San Diego, USA) in accordance with manufacturer's instructions.

Antioxidant enzyme activity assays. GPx activity and catalase enzymatic activity was measured in monocyte-derived macrophage lysates using commercially available kits (Cayman Chemical Company, Ann Arbor, USA) in accordance with manufacturer's instructions. Enzyme activity was expressed per $\mu \mathrm{g}$ protein ${ }^{53}$.

Free radical-scavenging activity assay. The free radical-scavenging activities of $80 \mu \mathrm{M} \mathrm{DHA}, \mathrm{EPA}$ and OA were examined using a colorimetric 1,1-diphenyl-2picrylhydrazyl (DPPH) assay as previously described ${ }^{54}$. Briefly, fatty acids and positive controls (BHT $227 \mu \mathrm{M}$; quercetin $50 \mu \mathrm{M}$ ) were incubated with methanolic DPPH solutions $\left(100 \mu \mathrm{M} ; 30 \mathrm{~min} ; 22^{\circ} \mathrm{C}\right)$ and absorbance was measured at $518 \mathrm{~nm}$. A methanolic solution of DPPH $(100 \mu \mathrm{M})$, decayed in the presence of $0.5 \mathrm{mM}$ ascorbic acid to allow clearance of colour, was used for background correction. Results were expressed as percentage of a negative control using the following equation:

$$
\mathrm{DPPH}-\text { scavenging activity }(\%)=100-\left[\left(\frac{\text { Blank-adjusted absorbance of sample }}{\text { Blank-adjusted absorbance of negaticve control }}\right) \times 100\right]
$$

RNA isolation and real-time quantitative PCR. Human blood derived monocytes were harvested and cultured as before. On day 7 of culture, adherent macrophages were exposed to a $1 \mathrm{~h}$ treatment with albumin $(80 \mu \mathrm{M}$, control cells) or DHA $(80 \mu \mathrm{M})$. Treated cells were incubated with hemin $(20 \mu \mathrm{M}$; Sigma) and stimulated with IFN- $\gamma(20 \mathrm{ng} / \mathrm{ml})$ and LPS $(1 \mu \mathrm{g} / \mathrm{ml})$ for $24 \mathrm{~h}$ to provoke super production of HO- $1^{55}$. Supernatants were collected, centrifuged and aliquoted as before. Cells were rinsed with DPBS and a $300 \mu l$ aliquot of RNALater RNA Stabilisation Reagent (Qiagen) was added to each well. Adherent cells were harvested by scraping and cells were cooled at $4{ }^{\circ} \mathrm{C}$ for $24 \mathrm{~h}$ followed by transfer to $-20^{\circ} \mathrm{C}$ for storage until analysis. Total RNA was extracted from samples using the Isolate II RNA mini kit (Bioline) prior to generation of cDNA using the SensiFAST cDNA synthesis kit (Bioline) and amplification of samples against transcripts by real-time quantitative PCR using the SensiMix SYBR No-Rox kit (Bioline) and a Rotor-Gene Q thermal cycler (Qiagen). Primers were from Sigma and included HO-1 forward 5'CCAGCAACAAAGTGCAAGATTC $3^{\prime}$, HO-1 reverse $5^{\prime}$ TCACATGGCATAAAGCCCTACAG $3^{\prime 56}$ and GAPDH forward 5'GGGGGAGCCAAAAGGGTCATCATCT $3^{\prime}$, GAPDH reverse $5^{\prime}$ GAGGGGCCATCCACAGTCTTC $3^{\prime 27}$. No template controls were run in each reaction and no contamination was observed. Normalisation points included a) spectrophotometric RNA quantification (Nanodrop, ND100), b) inclusion of a reference sample in each run and c) determination of mRNA levels of an internal control (GAPDH) for all samples. Quantitation of relative gene expression was based on the comparative threshold cycle method $\left(2^{-\Delta \Delta \mathrm{Ct}}\right)^{58}$ with raw data normalised to GAPDH.

Data analysis. Continuous demographic variables were compared using a student's t-test and are presented as mean \pm SD. Categorical demographic variables were compared using a Fisher's exact test and data are presented as number (percentage). Experimental data are presented as mean \pm SEM. Data were assessed to determine normality (Shapiro-Wilk test) and homogeneity of variance (Levene statistic). Where data followed Gaussian distribution, data were assessed using a student's t-test, assuming equal or unequal variance as determined by the Levene statistic. Where the null hypothesis for the Shapiro-Wilk test was rejected, data were analysed using the Mann Whitney $U$ test. Outliers in macrophage supernatant cytokine data (TNF- $\alpha \mathrm{n}=2, \mathrm{IL}-6 \mathrm{n}=3$, IL-10 $\mathrm{n}=2$ and IL-1 $\beta \mathrm{n}=2$ ) were identified using the extreme studentised deviate many-outlier procedure ${ }^{59}$ and excluded from analysis. For U937 experiments, significance was determined using one-way ANOVA corrected for multiple comparisons with Sidak test. Statistical significance was set at $\mathrm{p}<0.05$.

\section{References}

1. Burr, M. L. et al. Effects of changes in fat, fish, and fibre intakes on death and myocardial reinfarction: diet and reinfarction trial (DART). Lancet 2, 757-761 (1989).

2. Wang, C. et al. n-3 Fatty acids from fish or fish-oil supplements, but not $\alpha$-linolenic acid, benefit cardiovascular disease outcomes in primary-and secondary-prevention studies: a systematic review. Am. J. Clin. Nutr. 84, 5-17 (2006).

3. Massaro, M. et al. The omega-3 fatty acid docosahexaenoate attenuates endothelial cyclooxygenase- 2 induction through both NADP (H) oxidase and PKC $\varepsilon$ inhibition. Proc. Natl. Acad. Sci. 103, 15184-15189 (2006).

4. Yang, Y.-C. et al. Docosahexaenoic acid inhibition of inflammation is partially via cross-talk between Nrf2/heme oxygenase 1 and IKK/NF-кB pathways. J. Nutr. Biochem. 24, 204-212 (2013).

5. Carrepeiro, M. M. et al. Effect of n-3 fatty acids and statins on oxidative stress in statin-treated hypercholestorelemic and normocholesterolemic women. Atherosclerosis 217, 171-178 (2011).

6. Bouzidi, N. et al. Effects of omega-3 polyunsaturated fatty-acid supplementation on redox status in chronic renal failure patients with dyslipidemia. J. Ren. Nutr. 20, 321-328 (2010).

7. Calviello, G., Serini, S. \& Palozza, P. n-3 polyunsaturated fatty acids as signal transduction modulators and therapeutical agents in cancer. Curr. Signal Transduct. Ther. 1, 255-271 (2006).

8. Lands, W. Biochemistry and physiology of n-3 fatty acids. FASEB J. 6, 2530-2536 (1992).

9. Lee, J. Y. et al. Differential modulation of Toll-like receptors by fatty acids preferential inhibition by n-3 polyunsaturated fatty acids. J. Lipid Res. 44, 479-486 (2003). 
10. Kliewer, S. A. et al. Fatty acids and eicosanoids regulate gene expression through direct interactions with peroxisome proliferatoractivated receptors $\alpha$ and $\gamma$. Proc. Natl. Acad. Sci. 94, 4318-4323 (1997).

11. Oh, D. Y. et al. GPR120 is an omega-3 fatty acid receptor mediating potent anti-inflammatory and insulin-sensitizing effects. Cell 142, 687-698 (2010).

12. Serhan, C. Systems approach to inflammation resolution: identification of novel anti-inflammatory and pro-resolving mediators. J. Thromb. Haemost. 7, 44-48 (2009).

13. Meital, L. T., Sandow, S. L., Calder, P. C. \& Russell, F. D. Abdominal aortic aneurysm and omega-3 polyunsaturated fatty acids: Mechanisms, animal models, and potential treatment. Prostaglandins Leukot. Essent. Fatty Acids 118, 1-9 (2017).

14. Zhang, M. et al. Omega-3 fatty acids protect the brain against ischemic injury by activating Nrf2 and upregulating heme oxygenase 1. J. Neurosci. 34, 1903-1915 (2014).

15. Kusunoki, C. et al. Omega-3 polyunsaturated fatty acid has an anti-oxidant effect via the Nrf-2/HO-1 pathway in 3T3-L1 adipocytes. Biochem. Biophys. Res. Commun. 430, 225-230 (2013).

16. Ishikado, A. et al. 4-Hydroxy hexenal derived from docosahexaenoic acid protects endothelial cells via Nrf2 activation. PLoS ONE 8, e69415 (2013).

17. Origassa, C. \& Camara, N. Cytoprotective role of heme oxygenase-1 and heme degradation derived end products in liver injury. World J. Hepatol. 5, 541-549 (2013).

18. Abraham, N. G. \& Kappas, A. Heme oxygenase and the cardiovascular-renal system. Free Radic. Biol. Med. 39, 1-25 (2005).

19. Hawkes, W. C. \& Alkan, Z. Regulation of redox signaling by selenoproteins. Biol. Trace Elem. Res. 134, 235-251 (2010).

20. Lubos, E., Loscalzo, J. \& Handy, D. E. Glutathione peroxidase-1 in health and disease: from molecular mechanisms to therapeutic opportunities. Antioxid. Redox. Signal. 15, 1957-1997 (2011).

21. Kadiiska, M. et al. Biomarkers of oxidative stress study II: are oxidation products of lipids, proteins, and DNA markers of CCl 4 poisoning? Free Radic. Biol. Med. 38, 698-710 (2005).

22. Saraswathi, V. et al. Fish oil increases cholesterol storage in white adipose tissue with concomitant decreases in inflammation, hepatic steatosis, and atherosclerosis in mice. J. Nutr. 137, 1776-1782 (2007).

23. Zúñiga, J. et al. Protection against in vivo liver ischemia-reperfusion injury by $\mathrm{n}-3$ long-chain polyunsaturated fatty acids in the rat. Free Radic. Res. 44, 854-863 (2010).

24. Mori, T. A. et al. Effect of eicosapentaenoic acid and docosahexaenoic acid on oxidative stress and inflammatory markers in treatedhypertensive type 2 diabetic subjects. Free Radic. Biol. Med. 35, 772-781 (2003).

25. Barden, A. E. et al. n-3 fatty acids reduce plasma 20-hydroxyeicosatetraenoic acid and blood pressure in patients with chronic kidney disease. J. Hypertens. 33, 1947-1953 (2015).

26. Davis, T. A., Gao, L., Yin, H., Morrow, J. D. \& Porter, N. A. In vivo and in vitro lipid peroxidation of arachidonate esters: the effect of fish oil $\omega$-3 lipids on product distribution. J. Am. Chem. Soc. 128, 14897-14904 (2006).

27. Russell, F. et al. Suppressed oxidative stress response in abdominal aortic aneurysm macrophages exposed to lipopolysaccharide. Australian Vascular Biology Society meeting, Hobart (2016)

28. Morrow, J. D., Awad, J. A., Boss, H. J., Blair, I. A. \& Roberts, L. J. Non-cyclooxygenase-derived prostanoids (F2-isoprostanes) are formed in situ on phospholipids. Proc. Natl. Acad. Sci. 89, 10721-10725 (1992).

29. Milne, G. L., Dai, Q. \& Roberts, L. J. The isoprostanes-25 years later. Biochim. Biophys. Acta 1851, 433-445 (2015).

30. Ferguson, J. F. et al. Omega-3 polyunsaturated fatty acids attenuate inflammatory activation and alter differentiation in human adipocytes. J. Nutr. Biochem. 64, 45-49 (2019).

31. Mocellin, M. C., Fernandes, R., Chagas, T. R. \& Trindade, E. B. A meta-analysis of n-3 polyunsaturated fatty acids effects on circulating acute-phase protein and cytokines in gastric cancer. Clin. Nutr. 37, 840-850 (2018).

32. Körner, A. et al. Resolution of inflammation and sepsis survival are improved by dietary $\Omega-3$ fatty acids. Cell Death Differ. 25, 421-431 (2018)

33. Mickleborough, T. D., Sinex, J. A., Platt, D., Chapman, R. F. \& Hirt, M. The effects PCSO-524 ${ }^{\circledR}$, a patented marine oil lipid and omega-3 PUFA blend derived from the New Zealand green lipped mussel (Perna canaliculus), on indirect markers of muscle damage and inflammation after muscle damaging exercise in untrained men: a randomized, placebo controlled trial. J. Int. Soc. Sports Nutr. 12, 10 (2015).

34. Mori, T. A. Effect of fish and fish oil-derived omega-3 fatty acids on lipid oxidation. Redox Rep. 9, 193-197 (2013).

35. Massaro, M., Scoditti, E., Carluccio, M. A. \& De Caterina, R. Basic mechanisms behind the effects of $\mathrm{n}-3$ fatty acids on cardiovascular disease. Prostaglandins Leukot. Essent. Fatty Acids 79, 109-115 (2008).

36. Aikawa, T. et al. Low Serum Levels of EPA are Associated with the Size and Growth Rate of Abdominal Aortic Aneurysm. J. Atheroscler. Thromb. 24, 912-920 (2017).

37. Wales, K. M. et al. N-3 PUFAs protect against aortic inflammation and oxidative stress in angiotensin II-infused apolipoprotein $\mathrm{E}^{-1-}$ mice. PLoS ONE 9, e112816 (2014).

38. Kavazos, K. et al. Dietary supplementation with omega-3 polyunsaturated fatty acids modulate matrix metalloproteinase immunoreactivity in a mouse model of pre-abdominal aortic aneurysm. Heart Lung Circ. 24, 377-385 (2015).

39. Golledge, J., Muller, J., Daugherty, A. \& Norman, P. Abdominal aortic aneurysm: pathogenesis and implications for management. Arterioscler. Thromb. Vasc. Biol. 26, 2605-2613 (2006).

40. Kent, K. C. et al. Analysis of risk factors for abdominal aortic aneurysm in a cohort of more than 3 million individuals. J. Vasc. Surg. 52, 539-548 (2010).

41. Meital, L. T. et al. $\mathrm{n}-3$ PUFAs improve erythrocyte fatty acid profile in patients with small AAA: a randomized controlled trial. J. Lipid Res. 60, 1154-1163 (2019).

42. Tardivel, S. et al. Protective effects of EPA and deleterious effects of DHA on eNOS activity in Ea hy 926 cultured with lysophosphatidylcholine. Lipids 44, 225-235 (2009).

43. Sparks, S. M. et al. Identification of diarylsulfonamides as agonists of the free fatty acid receptor 4 (FFA4/GPR120). Bioorg. Med. Chem. Lett. 24, 3100-3103 (2014).

44. Drummond, G. S. \& Kappas, A. Prevention of neonatal hyperbilirubinemia by tin protoporphyrin IX, a potent competitive inhibitor of heme oxidation. Proc. Natl. Acad. Sci. 78, 6466-6470 (1981).

45. Meital, L. T. et al. A simple and effective method for the isolation and culture of human monocytes from small volumes of peripheral blood. J. Immunol. Methods 472, 75-78 (2019).

46. Ambrozova, G., Pekarova, M. \& Lojek, A. Effect of polyunsaturated fatty acids on the reactive oxygen and nitrogen species production by raw 264.7 macrophages. Eur. J. Nutr. 49, 133-139 (2010).

47. Liu, Y. et al. The fish oil ingredient, docosahexaenoic acid, activates cytosolic phospholipase A2 via GPR120 receptor to produce prostaglandin E2 and plays an anti-inflammatory role in macrophages. Immunology 143, 81-95 (2014).

48. Marangoni, F. et al. Changes of n-3 and n-6 fatty acids in plasma and circulating cells of normal subjects, after prolonged administration of 20: 5 (EPA) and 22: 6 (DHA) ethyl esters and prolonged washout. Biochim. Biophys. Acta Lipids Lipid Metab. 1210, 55-62 (1993).

49. Vikatmaa, P. et al. Chlamydial lipopolysaccharide (cLPS) is present in atherosclerotic and aneurysmal arterial wall-cLPS levels depend on disease manifestation. Cardiovasc. Pathol. 19, 48-54 (2010).

50. Juvonen, J. et al. Demonstration of Chlamydia pneumoniae in the walls of abdominal aortic aneurysms. J. Vasc. Surg. 25, 499-505 (1997). 
51. Karlsson, L., Gnarpe, J., Bergqvist, D., Lindbäck, J. \& Pärsson, H. The effect of azithromycin and Chlamydophilia pneumonia infection on expansion of small abdominal aortic aneurysms-A prospective randomized double-blind trial. J. Vasc. Surg. 50, 23-29 (2009).

52. Nyberg, A., Skagius, E., Nilsson, I., Ljungh, A. \& Henriksson, A. E. Lack of association between Chlamydophila pneumoniae seropositivity and abdominal aortic aneurysm. Vasc. Endovascular Surg. 41, 246-248 (2007).

53. Lowry, O., Rosebrough, N., Farr, A. \& Randall, R. Protein measurement with the Folin phenol reagent. J. Biol. Chem. 193, 265-275 (1951).

54. Hamilton, K. D., Brooks, P. R., Ogbourne, S. M. \& Russell, F. D. Natural products isolated from Tetragonula carbonaria cerumen modulate free radical-scavenging and 5-lipoxygenase activities in vitro. BMC Complement. Altern. Med. 17, 232 (2017).

55. Srisook, K. et al. CO from enhanced $\mathrm{HO}$ activity or from CORM-2 inhibits both $\mathrm{O} 2-$ and NO production and downregulates HO- 1 expression in LPS-stimulated macrophages. Biochem. Pharmacol. 71, 307-318 (2006).

56. Maruyama, A., Mimura, J., Harada, N. \& Itoh, K. Nrf2 activation is associated with Z-DNA formation in the human HO-1 promoter. Nucleic Acids Res. 41, 5223-5234 (2013).

57. Long, J., Zhao, J., Yan, Z., Liu, Z. \& Wang, N. Antitumor effects of a novel sulfur-containing hydroxamate histone deacetylase inhibitor H40. Int. J. Cancer 124, 1235-1244 (2009).

58. Schmittgen, T. D. \& Livak, K. J. Analyzing real-time PCR data by the comparative C T method. Nat. Protoc. 3, 1101-1108 (2008).

59. Rosner, B. Percentage points for a generalized ESD many-outlier procedure. Technometrics 25, 165-172 (1983).

\section{Acknowledgements}

This work was supported by Wishlist - Sunshine Coast Health Foundation, The Cluster for Biomedical Innovation and the School of Health and Sport Science, University of the Sunshine Coast. JG holds a Practitioner Fellowship from the National Health and Medical Research Council (1117061) and a Senior Clinical Research Fellowship from the Queensland Government, Australia.

\section{Author Contributions}

Conception of the study (L.T.M., M.T.W., M.P., K.S., R.M., A.K., J.G., T.G.B., C.D.A., F.D.R.); Design of the study (L.T.M., A.K., C.D.A., F.D.R.); Sample acquisition (L.T.M., M.T.W., M.P., K.S., R.M., J.G., F.D.R.); Data acquisition (L.T.M., A.K., F.D.R.); Data analysis (L.T.M., A.K., T.G.B., C.D.A., F.D.R.); Data interpretation (L.T.M., A.K., J.G., T.G.B., C.D.A., F.D.R.); Manuscript preparation (L.T.M., A.K., J.G., T.G.B., C.D.A., F.D.R.).

\section{Additional Information}

Competing Interests: The authors declare no competing interests.

Publisher's note: Springer Nature remains neutral with regard to jurisdictional claims in published maps and institutional affiliations.

(c) (i) Open Access This article is licensed under a Creative Commons Attribution 4.0 International License, which permits use, sharing, adaptation, distribution and reproduction in any medium or format, as long as you give appropriate credit to the original author(s) and the source, provide a link to the Creative Commons license, and indicate if changes were made. The images or other third party material in this article are included in the article's Creative Commons license, unless indicated otherwise in a credit line to the material. If material is not included in the article's Creative Commons license and your intended use is not permitted by statutory regulation or exceeds the permitted use, you will need to obtain permission directly from the copyright holder. To view a copy of this license, visit http://creativecommons.org/licenses/by/4.0/.

(c) The Author(s) 2019 